\title{
Las ampliaciones de la Unión Europea hacia Europa del este: impacto político, económico y social y nuevos nacionalismos
}

\section{Pedro Manuel Rodríguez Suárez* Gustavo López Ángel**}

\section{RESUMEN}

Este artículo analiza el impacto que ha tenido la membresía de la UE en los países de Europa del Este. Las ampliaciones de la UE hacia Europa del Este, han transformado radicalmente a los países ex socialistas europeos. Asimismo, han contribuido a terminar con el orden europeo que fue establecido en el viejo continente, después de la segunda guerra mundial. Por otro lado, este ensayo efectúa un estudio comparativo en relación con el crecimiento y el desarrollo económico entre los países de Europa del este que actualmente forman parte de la UE y los países de la "nueva Europa del este", que no son miembros de dicha organización. Aunado a lo anterior, evalúa los "nuevos nacionalismos" y el auge de los partidos políticos de ultra derecha en Europa. Desde la perspectiva teórica, este artículo se sustenta con la teoría

\footnotetext{
* Licenciado en relaciones internacionales por la Universidad Iberoamericana, especialidad en estudios europeos por el Itam y doctor en estudios de integración europea por la Universidad de Varsovia, Polonia. Profesor-investigador de relaciones internacionales, Benemérita Universidad Autónoma de Puebla, México. Miembro titular del Consejo de Investigación y Estudios de Posgrado de la Vicerrectoría de Investigación y Estudios de Posgrado de la Benemérita Universidad Autónoma de Puebla, México. Miembro del grupo de investigación: Conflictos Socioestructurales y Reconfiguraciones Regionales, Buap, (México) [pedrosuarezbuap@yahoo.com.mx].

** Licenciado en antropología social por el Colegio de Antropología Social, Benemérita Universidad Autónoma de Puebla. Maestría en ciencias antropológicas, Universidad Autónoma Metropolitana y doctorado en ciencias antropológicas por la Universidad Autónoma Metropolitana. Miembro del Sistema Nacional de Investigadores, ConacytMéxico. Profesor-investigador de tiemplo completo en la Benemérita Universidad Autónoma de Puebla, México. Miembro del grupo de investigación: Conflictos Socioestructurales y Reconfiguraciones Regionales, Buap, (México) [mixteca_migration@hotmail.com].
}

Recibido: 10 de abril de 2018 / Modificado: 15 de junio de 2018 / Aceptado: 10 de julio de 2018.

Para citar este artículo:

Rodríguez Suárez, P. M., y López Ángel, G. (2018). Las ampliaciones de la Unión Europea hacia Europa del este: impacto político, económico y social y nuevos nacionalismos. OASIS, 28, pp. 97-119.

Dor: https://doi.org/10.18601/16577558.n28.07 
de la Seguridad Compleja que postula Barry Buzan y Ole Waever.

Palabras clave: Unión Europea, ampliaciones, teoría de la seguridad compleja, Europa del Este y nacionalismos.

\section{The enlargements of the European Union towards Eastern Europe: new nationalisms and the political, economic and social impact}

\section{ABSTRACT}

This article analyzes the impact that the EU membership has had in the countries of Eastern Europe. The enlargements of the EU towards Eastern Europe, have radically transformed the former European socialist countries. They have also contributed to end the European order that was established in the old continent, after the Second World War. On the other hand, this article makes a comparative study in relation to growth and economic development between the Eastern European countries that are currently part of the EU and the countries of the "new Eastern Europe", which are not members of the aforementioned organization. In addition to the above, it evaluates the "new nationalisms" and the rise of ultra-right political parties in Europe. From a theoretical perspective, this article is supported by the theory of Complex Security posed by Barry Buzan and Ole Waever.

Key words: European Union, enlargements, complex security theory, Eastern Europe and nationalisms.

\section{INTRODUCCIÓN}

Este artículo efectúa un análisis del impacto que ha tenido la membresía de la UE en los países de Europa del este, particularmente en tres rubros: político, económico y social. Por otro lado, el autor efectúa un estudio comparativo referente al crecimiento y el desarrollo económico entre los países de Europa del este que son miembros de la UE y los países de la "nueva Europa del este", que no pertenecen a dicha organización. En este sentido, se hace referencia a los países de la "nueva Europa del este", que no son miembros de dicha organización, cuyo crecimiento económico ha sido muy endeble, debido a que no gozan de los beneficios inherentes a la integración económica europea. Finalmente, se evalúan los nacionalismos y los partidos políticos de ultra derecha que han surgido en los últimos años en Europa occidental, así como en los nuevos miembros de la UE de Europa del este, que responsabilizan a Bruselas en relación con las problemáticas que enfrentan sus sociedades, tales como: el desempleo, la migración indocumentada, la pérdida de soberanía, las crisis económicas, el arribo masivo de refugiados políticos, así como de la pérdida de la "pureza y de los valores europeos". Las políticas y el discurso político racista, xenofóbico y socialmente excluyente de estos partidos políticos particularmente en Hungría, Polonia, así como en la República Checa, han llamado la atención de la Comisión Europea, así como de algunos miembros de la UE, que apelan constantemente en aras de sancionar a estos países por sus políticas ultra nacionalistas que amenazan los principios y valores esenciales de la UE relativos al respeto por el Estado de derecho, los derechos humanos y de las minorías. 


\section{METODOLOGÍA}

La hipótesis que acompaña este trabajo es de tipo descriptiva, debido a que pronostica un fenómeno y posee tres argumentos fundamentales. El fenómeno que se pronostica sustenta los beneficios que ha tenido la membresía de la UE en los países de Europa del este. En este sentido, el primer argumento hace alusión a que si estos países no se hubiesen incorporado en dicha organización, con seguridad hoy en día prevalecería in situ la inestabilidad política, el poco crecimiento económico, así como los conflictos étnicos, lo que, sin duda alguna, hubiera tenido repercusiones muy serias hacia la estabilidad política de toda Europa. El segundo argumento alude a que la membresía de la UE ha contribuido a transformar radicalmente a los nuevos miembros de la UE, fenómeno que no ha sucedido en los países de la "nueva Europa del este", en donde el desarrollo y el crecimiento económico han sido muy endebles, lo que ha repercutido en el incremento de la inestabilidad política, los conflictos étnicos e inclusive en la fragmentación de los Estados. Asimismo, el poco crecimiento y desarrollo económico ha propiciado el surgimiento de partidos políticos de ultra derecha y de agrupaciones sociales de ultra nacionalistas, que han contribuido a incrementar la inestabilidad política en los países de la "nueva Europa del este". El tercer y último argumento que sustenta esta hipótesis es que a pesar de los grandes beneficios que han obtenido los países de Europa del este gracias a su membresía en la UE, una nueva corriente de nacionalismos y partidos políticos de ultra derecha, rechazan y responsabilizan a la UE de los problemas que afectan a sus sociedades, principalmente el desempleo, la migración indocumentada, el arribo masivo de refugiados políticos, así como la pérdida de soberanía. Estos partidos políticos existen en casi todos los miembros de la UE, empero, principalmente en Alemania, Dinamarca, Francia, el Reino Unido, Hungría y Polonia. Sin duda alguna, los partidos políticos de ultra derecha y los nacionalismos de ultranza pueden generar inestabilidad política en la UE e inclusive poner en tela de juicio sus cuatro libertades. En suma, libertad de movimiento de personas, capitales, bienes y servicios.

Este artículo posee tres objetivos fundamentales. El primero: evalúa el impacto que ha tenido la membresía de la UE en los países de Europa del este desde la perspectiva política, social y económica. El segundo: analiza los partidos de ultra derecha y los nacionalismos radicales que han surgido en los nuevos miembros de la UE de Europa del este. En relación con este objetivo se pretende evaluar las características que poseen dichos nacionalismos, sus bases ideológicas, así como los argumentos políticos y económicos que defienden y que les han propiciado un gran número de seguidores. Por lo tanto, hoy en día ocupan posiciones políticas de primer orden, en algunos miembros de la UE de Europa occidental y en algunos miembros de dicha organización de Europa del este, tales como Hungría y Polonia. El tercer y último objetivo, interpreta teóricamente las ampliaciones de la UE hacia Europa del este desde la perspectiva de la teoría de la seguridad compleja.

Este ensayo se divide en tres secciones. En la primera parte se utiliza la teoría de la seguridad compleja que postula Barry Buzan y Ole Waever con la finalidad de encontrar una res- 
puesta teórica hacia las ampliaciones de la UE hacia Europa del este. En la segunda, se hace alusión al impacto que ha tenido la membresía de la UE en los países de Europa del este, y en la tercera, se aborda el surgimiento y fortaleza de los partidos políticos de ultra derecha y los nacionalismos radicales que han surgido en los miembros de la UE de Europa del este.

\section{MARCO TEÓRICO: TEORÍA DE LA SEGURIDAD COMPLEJA}

Esta teoría es presentada en el libro: Regions and Powers: a guide to global security order (Buzan y Waever, 2013). La teoría de la seguridad compleja interpreta los problemas de seguridad que aparecieron en el escenario internacional al concluir la guerra fría. Sin embargo, para efectos de este artículo dicha teoría se utilizará únicamente para comprender teóricamente las ampliaciones de la UE hacia Europa del este.

Desde la perspectiva de esta teoría el fin de la guerra fría connotó un cambio radical en torno a los problemas de seguridad del viejo continente. Barry Buzan y Ole Waever fundamentan su teoría desde las perspectivas del neorrealismo, el globalismo y el regionalismo. Desde su punto de vista, el regionalismo está más cerca del neorrealismo que del globalismo debido a que el regionalismo constituye una respuesta al fenómeno de la globalización, así como a los problemas de seguridad que enfrentan hoy día las regiones.

El centro de estudio de la teoría de la seguridad compleja se concentra en los complejos de seguridad regional, que aparecen en las obras People States and Fear: an agenda for international security in the post cold war era (Buzan,
2007, p. 17) y Security: a New Framework for Analysis (Buzan, Waever y de Wildem, 1997, pp. 23-24). Cabe mencionar que en los complejos de seguridad los actores se identifican como "interdependientes"; por lo tanto, crean una "identidad colectiva" en aras de contrarrestar las amenazas que eventualmente podrían afectar su seguridad y estabilidad política. En este contexto, los actores que pertenecen a los complejos de seguridad consideran que los problemas inherentes a su seguridad no pueden resolverse de manera aislada y la respuesta más efectiva es actuar de manera colectiva. En Europa, la UE y la Otan representan los complejos de seguridad más importantes. Aunque la primera no es una organización de seguridad militar, proporciona hacia sus miembros seguridad económica. La segunda concede seguridad militar hacia sus 29 miembros. Cabe hacer alusión a que la adhesión de los países de Europa del este en ambas organizaciones, es considerada como la respuesta más efectiva que proporcionó Europa occidental hacia los problemas de seguridad que enfrentó el continente europeo después del fin de la guerra fría, o bien, de la fragmentación ideológica de Europa.

Barry Buzan y Ole Waever mantienen la convicción de que los actores que intervienen para propiciar estabilidad política en Europa superan la concepción tradicionalista y estadocéntrica. Barry Buzan y Ole Waever crean una relación entre el realismo y el constructivismo. Asimismo, consideran que el realismo tradicional es muy limitado para comprender los problemas que afectan la seguridad del viejo continente. Por lo tanto, la teoría de la seguridad compleja aborda los estudios de seguridad desde una perspectiva intersubjetiva, en la cual 
la opinión pública juega un papel fundamental que legitimiza que un fenómeno de seguridad sea percibido como un "riesgo" hacia la seguridad colectiva.

Cabe subrayar que, durante las ampliaciones de la UE hacia el este de Europa, el Estado, los actores no estatales, así como la participación de la opinión pública han tenido un papel fundamental para legitimar dichas ampliaciones. La mayoría de estos actores han sido de la convicción inherentes a los beneficios que obtendrían los países de Europa occidental en relación con dichas ampliaciones, en particular en materia de seguridad y estabilidad política. Desde la perspectiva de los ex 15 miembros de la UE y de la opinión pública de Europa occidental, una Europa fuertemente integrada, que posea mecanismos de cooperación, que se encuentren respaldados con una fuerte institucionalización, creará lo que Barry Buzan y Ole Waever denominan como "identidad comunitaria". Dicha identidad comunitaria contribuiría a cimentar las bases para que Europa sea más segura, próspera y estable, así como para contrarrestar los problemas de seguridad que enfrenta el viejo continente en el siglo XXI.

Resulta importante mencionar que en el siglo Xxi los problemas de seguridad que amenazan la estabilidad política de Europa los constituyen el tráfico de armas, la migración indocumentada, el éxodo masivo de refugiados políticos, el terrorismo, los partidos políticos de ultra derecha, los nacionalismos radicales, el racismo y la xenofobia; aunado a las autocracias y los conflictos étnicos y separatistas que se han presentado en Europa del este. En este orden de ideas, desde la perspectiva de la teoría de la seguridad compleja, la integración de los países de Europa del este en la UE y en la Otan contribuye, de manera decisiva, a enfrentar los problemas que afectan la estabilidad política de Europa occidental en el marco del siglo XXI.

\section{LAS AMPLIACIONES DE LA UE HACIA EUROPA DEL ESTE: IMPACTO POLÍTICO, ECONÓMICO Y SOCIAL}

Las ampliaciones de la UE hacia Europa del este han sido muy positivas debido a que han contribuido a fortalecer la estabilidad, la paz y la prosperidad in situ. Estas ampliaciones han transformado radicalmente a países en donde existía hasta hace poco tiempo un sistema político totalitario y economías centralizadas. Después de la caída del socialismo en este grupo de países predominaba el poco crecimiento económico, la inestabilidad política, las confrontaciones entre diferentes grupos étnicos, así como el surgimiento de los nacionalismos radicales. Este fenómeno tomó efecto con particular atención en las repúblicas bálticas, Ucrania, Moldavia, así como en la otrora Checoslovaquia y Yugoslavia.

Las ampliaciones de la UE hacia Europa del este son interpretadas por una cantidad bastante considerable de especialistas como uno de los mayores retos que ha enfrentado la UE en toda su historia, debido a que incorporó por primera vez a países con un nivel económico muy inferior en comparación al resto de los ex 15 miembros de la UE. Aunado a lo anterior, todos estos países se encontraban en lo que los especialistas denominan como "el período de transición”. En suma, la transición de sistemas 
políticos totalitarios y economías centralizadas a sistemas políticos democráticos y economías de mercado (Hill, 2002, p. 2).

Pocos años después de la caída de la URss y del bloque socialista europeo la UE estableció con los países de Europa del este acuerdo de libre comercio, que posteriormente se transformaron en los Acuerdos Europeos (AE). Los AE incrementaron el nivel de integración y establecieron la posibilidad en relación con el eventual ingreso de este grupo de países en la UE, debido a que tenían todo el derecho a integrarse en la UE, tal y como lo establece el artículo 49 del Tratado de la UE (1992). Sin embargo, su integración fue condicionada a cumplir con los criterios de adhesión que estableció el Consejo Europeo de Copenhague que tuvo efecto en 1993, que fueron los siguientes:

- Poseer sistemas políticos democráticos e instituciones políticas estables que garanticen el respeto al Estado de derecho.

- Respeto a los derechos humanos y de las minorías étnicas.

- Economías de mercado y habilidad para competir en el mercado comunitario.

- Capacidad para cumplir con las obligaciones de la membresía de la UE.

- La existencia de una economía de mercado en funcionamiento y la capacidad de hacer frente a la presión competitiva y las fuerzas del mercado dentro de la UE.

- Capacidad para asumir las obligaciones que se derivan de la adhesión, y poner en práctica y de manera eficaz las normas, estándares y políticas que forman parte del acervo comunitario.

- Aceptar los objetivos de la unión política, económica y monetaria.
Estos requisitos fueron muy difíciles de cumplir para los países ex socialistas de Europa, debido a que no estaban preparados para adoptarlos, por lo que la UE creó diferentes programas de cooperación en relación con su pre adhesión. Entre los más importantes resaltan: Polonia y Hungría: programa para la reconstrucción económica, el Banco Europeo para la Reconstrucción Económica y el Desarrollo, el Proceso de Estabilización y Asociación, así como, el Instrumento de Ayuda de Pre adhesión.

Para los países ex socialistas de Europa del este la membresía en la UE connotaba una quasi garantía vis-à-vis su crecimiento y desarrollo económico. Aunado a lo anterior, significaba integrarse al bloque económico más consolidado del mundo, terminar con el pasado totalitario y con las relaciones tan asimétricas que mantuvieron con Moscú por casi medio siglo. Asimismo, debido a su ingreso en la UE estos países accedieron de forma inmediata a los Fondos Estructurales y los Fondos de Cohesión que, sin duda alguna, fortaleció sus reformas estructurales. Cabe mencionar, que dichos fondos han sido esenciales para consolidar el sistema democrático, así como, las economías de mercado en los nuevos miembros de la UE.

Los países de Europa del este se han beneficiado considerablemente de su membresía en la UE, lo que se ve reflejado no solo con su crecimiento y el desarrollo económico, sino que también con el importante intercambio comercial que mantienen con la UE, así como con los miembros de la Asociación Europea de Libre Comercio (Aelc). Aunado a lo anterior, estos países han recibido una cantidad muy 
considerable de inversión extranjera directa (IED), principalmente de Alemania, Austria, Francia, Italia y el Reino Unido. En relación con el impacto de los Fondos Estructurales, estos fondos han sido utilizados para modernizar su infraestructura, mejorar las instituciones políticas, modernizar el sector agrícola, incrementar la calidad de la educación y de la salud pública, así como para incrementar las oportunidades laborales. En este contexto, la calidad de vida de millones de ciudadanos que viven en los nuevos miembros de la UE, se ha transformado radicalmente.

Por otro lado, una gran cantidad de ciudadanos de Europa del este han emigrado de manera legal hacia los países de Europa occidental. Sin embargo, este fenómeno no ha sido bien recibido por algunos miembros de la UE y es considerado como una de las principales variables en relación con el Brexit, así como con el incremento de los partidos políticos de ultra derecha y de los nacionalismos de ultranza en Europa occidental y en los nuevos miembros de la UE de Europa del este.

En los Estados miembros de la UE, en donde han tomado más poder los partidos políticos de ultra derecha, así como los movimientos sociales ultra nacionalistas resaltan: Francia, el Reino Unido, Polonia, Hungría, Italia y Dinamarca. Estos partidos políticos han incrementado su presencia, así como su influencia en el contexto político interno de sus países, y en las instituciones de la UE, como el Parlamento europeo. Aunado a lo anterior, se ha incrementado el número de eurodiputados que representan a los partidos políticos de extrema derecha.

A pesar del fortalecimiento de los nacionalismos y de las fuerzas políticas de ultra derecha en Europa occidental y en los nuevos miembros de la UE de Europa del Este, que como ya se mencionó, responsabilizan a Bruselas de los problemas que afectan a sus sociedades, el impacto que ha tenido la membresía de esta organización en este grupo de países ha sido mayúsculo. Desde esta perspectiva, dicho impacto puede ser clasificado desde las siguientes aristas: política, económica y social.

\section{Impacto político}

Después de la caída del bloque socialista, los países de Europa del este no tuvieron otra opción más que integrarse en la UE, de lo contrario hubiesen quedado excluidos del desarrollo político, económico y social, que prevalece en Europa occidental.

Sin duda alguna, uno de los impactos políticos más importantes inherentes a la membresía de la UE ha sido la consolidación del sistema político democrático y de las instituciones políticas, lo que ha contribuido a erradicar el sistema político totalitario. Cabe subrayar que este fenómeno no ha sucedido en los países de la "nueva Europa del este". En suma, Bielorrusia, Moldavia, Ucrania e inclusive en la propia Rusia (Doyle, 1986, p. 51), tal y como lo revelaron las elecciones presidenciales en Rusia que tuvieron efecto durante el 2018, que demostraron la fragilidad de la democracia rusa, que renovó el poder presidencial de Vladimir Putin hasta el 2024. Resulta importante mencionar que en materia de estudios europeos, se utiliza el concepto referente a la "nueva Europa del este", en aras de aludir a los países de Europa del este que no forman parte de la UE, ni tampoco de la Otan y que se encuen- 
tran en la zona de influencia de Rusia. Aunado a lo anterior, este grupo de países pertenecen, desde la óptica rusa, a su "cercano próximo" y todos ellos formaron parte de la URSs.

Cabe mencionar que la consolidación del sistema político democrático ha contribuido a fortalecer la estabilidad política y la participación de la sociedad civil. En este sentido, hoy en día en todos estos países predomina el sistema político democrático. Sin duda alguna, en Hungría, Polonia y la República Checa, que son los países más importantes de la región, los partidos políticos de ultra derecha y los nacionalismos de ultranza han ganado poder y espacios políticos en los últimos años, tal y como lo ejemplifica el triunfo del partido político "Fidesz Unión Cívica Húngara” y su polémico candidato Viktor Orbán, en las elecciones parlamentarias que tuvieron efecto en Hungría en el 2018. Aunado a lo anterior, en dichas elecciones el partido político de extrema derecha "Movimiento por una Hungría Mejor", logró colocarse como segunda fuerza política. En Polonia, también existen partidos políticos de ultra derecha y fuerzas sociales ultra nacionalistas, tales como: "La Acampada Nacional Radical" y "Juventud Pan-polaca”. Asimismo, el partido de ultra derecha "Partido Ley y Justicia" (PIS), domina el escenario político polaco. El pIs gobierna a Polonia que es el país más importante y más grande de los nuevos miembros de la UE, con mayoría absoluta desde 2015. En la República Checa, el partido de ultra derecha "Libertad y Democracia Directa” (SPD), liderado por Tomio Okamura, representa la segunda fuerza política de este país. Cabe mencionar que los partidos políticos de ultra derecha en este grupo de países han promovido leyes que ponen en riesgo los principios elementales en relación con el sistema político democrático. Por citar un ejemplo, en Polonia el "Partido Ley y Justicia” ha promulgado cambios en la constitución polaca para reformar el sistema judicial, así como el electoral. La Comisión Europea ha sancionado dichas reformas y las considera como "un peligro para el Estado de derecho y el sistema político democrático”. En Hungría, el partido político predominante "Fidesz Unión Cívica Húngara” y su líder Víktor Orbán han centralizado el sistema político. Asimismo, en su plataforma política han puesto la lucha en contra de la migración como el eje central de su discurso político, que es considerado por la Comisión Europea como notoriamente racista y xenofóbico. De manera similar, en la República Checa, el partido de ultra derecha "Libertad y Democracia Directa", liderado por Tomio Okamura ha convertido a la migración como el centro de su plataforma política. Aunado a lo anterior, difunde un discurso político totalmente xenofóbico y racista en contra de lo que considera como "la islamización de la República Checa”.

Resulta importante mencionar que aunque estos partidos políticos son similares entre sí, difieren en relación con su naturaleza y esencia. Sin embargo, la gran mayoría de dichos partidos se muestran en contra de la migración y son considerablemente "euroescépticos". En relación con su "euroescepticismo", consideran que la UE es la gran responsable de los problemas que enfrentan sus sociedades, tales como el desempleo, la migración documentada. 
Asimismo, no están de acuerdo con el lugar tan periférico en el que se encuentran sus países dentro de la UE.

A pesar del arribo de los nacionalismos y el gran poder que han logrado cosechar los partidos políticos de ultra derecha en los nuevos miembros de la UE de Europa del este (Pacce, M. \& Pacce, 2016, p. 23), actualmente existen in situ instituciones políticas consolidadas, el respeto por la libertad de expresión, los derechos humanos y de las minorías étnicas. Asimismo, después de la caída del socialismo ha surgido una gran diversidad de partidos políticos y de organizaciones no gubernamentales.

Debido a su pertenencia a la UE los países de Europa del este actualmente están comprometidos con poseer un sistema político democrático, buena gobernanza, instituciones políticas que garanticen el respeto al Estado de derecho, así como por los derechos humanos y las minorías. Este fenómeno ha marcado una gran diferencia entre este grupo de países y los países de la "nueva Europa del este" y que se encuentra que no son miembros de la UE y están ubicados geopolíticamente en el "cercano próximo" de Rusia.

Por otro lado, el ingreso de estos países en la UE ha contribuido a reforzar la seguridad y la estabilidad política en el viejo continente. Cabe mencionar que este grupo de países, por su ubicación geográfica, son de vital importancia para la seguridad de Europa debido a que se encuentran "entre las dos Europas" y porque son los miembros de la UE más cercanos a Rusia y a los países que comprenden la "nueva Europa del este".

Aunque el impacto político ha sido considerablemente exitoso, aún faltan por conso- lidar los sistemas políticos democráticos, así como las instituciones políticas, en particular en Bulgaria y Rumanía. Asimismo, en años recientes los países de Europa del este, miembros de la UE, han enfrentado crisis políticas y la parálisis electoral.

Otro de los retos que enfrentan los países de Europa del este, miembros de la UE, es la lucha en contra de la corrupción. Los problemas más graves inherentes a este flagelo se presentan nuevamente en los miembros más periféricos de la UE. En suma, Bulgaria y Rumanía. Otra problemática que se puede observar en este grupo de países es el nivel tan bajo de confianza que existe hacia las instituciones políticas de sus países. Por ejemplo, durante el 2008 solo el 16\% de los ciudadanos de los nuevos miembros de la UE expresaba "cierta confianza" hacia las instituciones políticas de sus países. Este porcentaje es relativamente inferior en comparación con el nivel de confianza que expresa la opinión pública de los miembros de la UE de Europa occidental. En este sentido, alrededor del 50\% de los ciudadanos de Europa occidental manifiesta su confianza hacia las instituciones políticas de sus países. En relación con los miembros de la UE que se ubican geográficamente en Escandinavia (Suecia, Dinamarca y Finlandia), alrededor del 95\% de la opinión pública expresa su confianza hacia las instituciones políticas de sus países (Lewis, 2006, p. 87). Resulta importante mencionar que la desconfianza hacia las instituciones políticas que expresan los ciudadanos de los nuevos miembros de la UE, demuestra que aún persiste cierto legado del pasado socialista.

Por otro lado, en términos políticos las ampliaciones de la UE hacia Europa del Este, 
significó el fin de la fragmentación ideológica de Europa que, como es bien conocido, permaneció por casi medio siglo. Aunado a lo anterior, los países de Europa del este se integraron a una comunidad de países en donde predomina la democracia, la estabilidad política, la prosperidad, la economía de mercado, el respeto por el Estado de derecho y en donde las diferencias que surgen entre los miembros de la UE se solucionan de manera institucionalizada. Cabe mencionar que este fenómeno es muy diferente en la "nueva Europa del este", en donde Rusia constituye el actor hegemónico y en donde las diferencias con los países que pertenecen a su "cercano próximo", se resuelven por medio de la imposición, la intimidación y, en el peor de los casos, con el uso de la fuerza bélica (Graham, 2009, p. 21).

Sin duda alguna, para la UE las ampliaciones hacia Europa del Este han connotado reforzar la estabilidad política, la paz, la seguridad y la prosperidad en el continente europeo. En realidad, dichas ampliaciones han connotado la estrategia política más importante que ha establecido Europa occidental para estabilizar a los países ex satélites de la URSS. Cabe hacer alusión a que este fenómeno es de suma importancia, en particular si se toma en consideración que al colapsar el bloque socialista europeo predominaba in situ, las democracias frágiles, el poco crecimiento económico, los problemas de minorías étnicas, así como la fragmentación política de un número considerable de Estados, como lo fue el caso de la otrora Checoslovaquia.

Por otro lado, Europa occidental hoy es políticamente mucho más fuerte, próspera y más estable que antes. Asimismo, el poder político de negociación de la UE a nivel internacional se ha incrementado tanto en los foros internacionales, así como en otras regiones del mundo, o bien, frente a otras potencias, principalmente Estados Unidos y China.

Aunado a lo anterior, el Muro de Berlín, que antes dividía al viejo continente en "dos Europas" ha desaparecido para siempre y ha surgido una "nueva Europa", en donde prevalece la paz, la estabilidad y la integración política y económica. A pesar del fenómeno Brexit y del surgimiento de los partidos políticos de ultraderecha y de los nacionalismos de ultranza que claman cada vez más por una Europa menos integrada y la renegociación de algunos acuerdos cruciales, como el Acuerdo de Schengen y de la Unión Económica Monetaria, la UE continúa siendo un referente de integración a nivel mundial, así como uno de los actores políticos más importantes del escenario internacional.

\section{Impacto económico}

El ingreso de los países de Europa del Este en la UE significó un cambio radical en el contexto de su comercio exterior. El comercio exterior de estos países en la época del socialismo se concentraba en los mercados del Consejo de Ayuda Mutua Económica (Comecon). En este sentido, hoy en día las interacciones económicas internacionales de este grupo de países se concentran en el mercado comunitario. Aunado a lo anterior, todas las barreras arancelarias hacia los mercados de los miembros de la UE han sido eliminadas. Todos estos países han adoptado los acuerdos comerciales que la UE ha establecido con terceros países, como el 
Acuerdo de Asociación Económica, Concertación Política y Cooperación entre México y la UE, así como el Acuerdo de Asociación entre Chile y la Unión Europea, lo que ha contribuido a que los nuevos miembros de la UE diversifiquen sus relaciones comerciales internacionales, particularmente con los socios económicos más importantes de la UE.

Por otra parte, la membresía de la de UE les ha proporcionado la "seguridad económica" que tanto deseaban obtener al finalizar el sistema socialista, debido a que su incorporación en la UE ha fortalecido, de manera considerable, el crecimiento y el desarrollo económico de este grupo de países. Sin embargo, la crisis económica que tuvo efecto durante el 2007 en la UE ha incrementado el euroescepticismo, el peso político de los partidos de ultra derecha, así como de los nacionalismos radicales. En este sentido, algunos segmentos de la sociedad civil de Europa del este han empezado a cuestionar la membresía en la UE y el respaldo de la opinión pública en relación con pertenecer a la UE ya no es tan fuerte como lo fue durante finales del siglo xx e inicios del xxi (Eurobarómetro, 2017).

Debido al ingreso de los países de Europa del este en la UE, hoy este bloque económico representa una de las economías más fuertes, grandes e importantes del mundo. En este sentido, a pesar de que Europa occidental es relativamente pequeña en comparación con otras potencias mundiales, como Estados Unidos, China o Rusia, genera el 25\% del PIB mundial. Por otro lado, de manera conjunta con Estados Unidos, ambos actores efectúan el $40 \%$ de los intercambios comerciales internacionales y representan el 60\% del PIB mundial. Las ampliaciones de la UE hacia Europa del este han incorporado al mercado comunitario a más de 100 millones de consumidores de esta Europa, que poseen un poder adquisitivo cada vez más fuerte. Entre los principales socios comunitarios de los nuevos miembros de la UE resaltan: Alemania, Austria, Italia, Francia y Reino Unido, así como los países escandinavos. Asimismo, el comercio interregional entre los nuevos miembros de la UE y los otrora 15 miembros de la Unión se ha incrementado en tres veces. Según la Comisión Europea, en 1999 las interacciones económicas entre este grupo de países y los ex 15 miembros de la UE representaban 17 millones de euros; para 2007 dichos intercambios comerciales se incrementaron en 500 millones de euros (Comisión Europea, 2009), lo que pone en evidencia que la integración económica ha sido todo un éxito (Weise, Bachtler y K. Toepel, 2001, p. 75).

La membresía de los países de Europa del este en la UE ha permitido que este grupo de países obtengan los beneficios que en términos económicos gozan los miembros de la UE; por lo tanto, sus bienes y servicios hoy en día tienen acceso a un mercado de más de 500 millones de consumidores. Cabe mencionar que un número considerable de miembros de la UE pertenecen a las sociedades más ricas y prósperas del mundo, tales como: Alemania, Dinamarca, Finlandia, Francia, Italia, Luxemburgo, Países Bajos, el Reino Unido y Suecia. Asimismo, no solo se ha establecido un área de libre comercio y se han eliminado todas las barreras arancelarias, sino que también se ha profundizado el intercambio del know-how; por lo tanto, las economías de este grupo de países son mucho más competitivas en comparación con la época socialista. 
Como se comentó con anterioridad, la mayor parte de la IED que ha llegado a estos países se concentra en la industria, los servicios, el sector energético, así como en las telecomunicaciones (Baas, y Brücker, 2011, pp. 47-70). El libre movimiento de capitales, bienes, servicios y de personas también ha contribuido a edificar economías más flexibles y competitivas, lo que ha permitido crear fuentes de empleo. Este fenómeno ha permitido que los precios de los bienes y servicios disminuyan y que la calidad de vida de los ciudadanos de Europa del este se incremente de manera considerable (Beacháin, Sheridan y Stan, 2012, p. 69).

En Polonia los efectos económicos en relación con la adhesión en la UE se hicieron evidentes poco después de su incorporación en dicha organización. Por ejemplo, el crecimiento económico se incrementó a un 6.5\% después de 2004, el índice de desempleo se redujo a un 20\% durante 2007 y para 2013 la tasa de desempleo disminuyó al 11\%. Asimismo, los salarios se incrementaron y 12 millones de nuevos empleos fueron generados, gracias al incremento de la IED (Zielonka, 2008, p. 58).

Para Hungría los beneficios económicos han sido muy notorios. De manera contraria a Polonia, su comercio exterior aumentó no solo con las economías del mercado comunitario, sino que también con otros países de Europa del este (Kellerman, 2006, p. 56). En Eslovenia, después de la integración a la UE se comenzó a desarrollar un mercado financiero, por lo que ha sido más fácil acceder a los capitales extranjeros que empezaron a estimular las actividades de importación y exportación de las pequeñas y medianas empresas. En Bulgaria, el рів nominal durante 2003 fue de
34628 millones de euros; para 2013 aumentó a 51030 millones de euros (Tupy, 2003, p. 86).

Por otro lado, los nuevos miembros de la UE de Europa del Este han sabido utilizar su membresía para incrementar su comercio internacional. En este sentido, han utilizado sus ventajas competitivas relativas a su ubicación geográfica y al costo de mano de obra, que es inferior en comparación con el resto de los miembros de la UE. Asimismo, Eslovaquia, Eslovenia, Estonia, Hungría, Letonia, Polonia y la República Checa pertenecen al grupo de economías emergentes más importantes del mundo, así como a organizaciones económicas internacionales cuyos miembros son las economías más ricas del escenario económico internacional, como la Organización para la Cooperación y el Desarrollo Económicos (Ocde). De nuevo aquí se puede encontrar otra gran diferencia entre los dos grupos de países que conforman actualmente a Europa del este. Al respecto, aunque Rusia no es miembro de la Ocde, pertenece al grupo de economías emergentes más importante del mundo. Sin embargo, Bielorrusia, Moldavia y Ucrania figuran entre las economías menos desarrolladas del continente europeo.

Los indicadores en relación con el PIB nominal y el PIB per cápita de las economías de los países de Europa del este, miembros de la UE y de Europa del Este que no son miembros de dicha organización, permite afirmar el planteamiento de la hipótesis de este artículo. Es decir, que después de la caída del bloque socialista y de la Unión de Repúblicas Socialistas Soviéticas (URSS), los países ex socialistas comenzaron a tomar rumbos muy diferentes. Es decir, que la membresía de los países de Europa 
del este en la UE ha contribuido a transformarlos radicalmente. Sin embargo, cada vez más se incrementan las asimetrías en términos de crecimiento y desarrollo económico, entre este grupo de países y los países de Europa del este que no forman parte de dicha organización.

El poco desarrollo y crecimiento económico en los países de la "nueva Europa del este", así como la ausencia de una real transformación política democrática, han repercutido muy seriamente en relación con la inestabilidad política, los conflictos étnicos, el incremento de los nacionalismos y las xenofobias $y$, en algunos casos, con las confrontaciones militares, tal y como sucedió en Moldavia en 1990 y en Ucrania en el 2014.

Finalmente, los nuevos miembros de la Unión se han beneficiado de los Fondos Estructurales y de los Fondos de Cohesión, así como de la cooperación interregional que existe en la UE para fomentar el desarrollo entre sus miembros. Cabe hacer alusión a que estos fondos han sido cruciales para transformar económicamente a los nuevos miembros de la UE de Europa del este, así como para romper con la "brecha" tan grande que existía entre este grupo de países y los ex 15 miembros de la UE.

Resulta importante mencionar que, a pesar de los beneficios tan considerables que han recibido este grupo de países en términos económicos, en relación con su membresía en la UE, las brechas salariales continúan siendo muy profundas, entre los nuevos miembros de la UE y los ex 15 miembros de dicha organización, motivo por el cual una cantidad muy considerable de ciudadanos de los nuevos miembros de la UE de Europa del Este, continúan migrando hacia los países más ricos de
Europa, tal y como sucede, con la migración polaca hacia el Reino Unido.

\section{Impacto social}

La integración de los países de Europa del este en la UE ha enriquecido culturalmente a este organismo debido a la diversidad cultural que existe entre los países ex socialistas de Europa y los países de Europa occidental. Resulta importante mencionar que a pesar de que estos países nunca fueron imperios de ultramar, como España, Francia, Portugal y el Reino Unido poseen un acervo cultural milenario. Aunado a lo anterior, las universidades e instituciones de investigación de los países de Europa del este miembros de la UE figuran entre las más antiguas de Europa. Asimismo, durante el socialismo existió un gran impulso hacia la música clásica, las artes, el ballet clásico, la literatura y el deporte, que continua hasta el día de hoy.

Por otro lado, la transformación social y cultural post-socialista ha sido mucho más rápida y efectiva en los países de Europa del este que se integraron en la UE, en comparación con los países de la "nueva Europa del este" que se encuentran fuera de dicha organización. Asimismo, la membresía de la UE ha permitido que los estudiantes de nivel de licenciatura y de posgrado puedan estudiar en 28 Estados miembros de la UE. El programa Erasmus ha facilitado la movilidad académica de estudiantes, académicos e investigadores entre las universidades de Europa occidental y de Europa del Este. Según sondeos de opinión pública, $84 \%$ de los estudiantes universitarios califican positivamente los resultados del programa Erasmus. Desde su punto de vista, dicho programa 
contribuye a incrementar la competitividad de los recursos humanos europeos (Ehea, 2014).

Por otro lado, el Acuerdo de Schengen y sus objetivos en relación con la apertura de fronteras y la libre circulación de personas ha tenido un impacto mayúsculo en los nuevos miembros de la UE, debido a que sus ciudadanos circulan libremente en los países miembros de la UE que pertenecen al espacio Schengen, así como en el territorio de los miembros de la Asociación Europea de Libre Comercio (Aelc). Este fenómeno ha permitido que se incrementen los contactos personales, así como profesionales entre los ciudadanos de Europa del este y Europa occidental.

Asimismo, una cantidad muy considerable de personas de Europa del este han emigrado de manera legal hacia los países más ricos y prósperos de la UE. La migración legal ha contribuido vis-à-vis al envío de remesas hacia los nuevos miembros de la UE. Estas remesas han generado fuentes de empleo y se han utilizado en su mayor parte en la industria de la construcción (Baas y Herbert, 2011, p. 38).

Finalmente, de acuerdo con el índice de desarrollo humano de la Organización de las Naciones Unidas (ONU), los países de Europa del este, miembros de la UE, han incrementado sus indicadores en términos de calidad de vida. Según la onu estos países poseen la mejor calidad de vida del mundo emergente (ONU, 2017), debido a que son considerados como "economías de alto desarrollo económico y social". A pesar de lo mencionado, las desigualdades sociales se incrementan cada vez más en los nuevos miembros de la UE, así como en los países de la "nueva Europa del este", fenómeno societal que no existía durante la época del "socialismo real".

\section{PARTIDOS POLÍTICOS DE ULTRA DERECHA Y NACIONALISMOS DE ULTRANZA EN LOS NUEVOS MIEMBROS DE LA UE DE EUROPA DEL ESTE}

En palabras de Raúl Araque Bejarano, "la ultraderecha y los nacionalismos radicales comienzan a hacer un fantasma que recorre a toda Europa" (Bejaron, 2016) En efecto, los partidos políticos de ultraderecha y las agrupaciones sociales caracterizadas por su nacionalismo de ultranza, han incrementado su peso político en prácticamente toda Europa occidental, así como en los nuevos miembros de la UE de Europa del este, a pesar de que como ya se mencionó, este último grupo de países es el que más se ha beneficiado de las ampliaciones de la UE.

Como partidos políticos de ultra derecha en Europa se alude científicamente a las agrupaciones políticas que se encuentran oficialmente institucionalizadas y que se caracterizan por defender y propagar ideologías de tipo conservador, ultra nacionalistas, y en ocasiones defienden el sistema político monárquico. Asimismo, no aceptan el principio de igualdad entre los ciudadanos y desde la perspectiva de algunos especialistas, son severamente elitistas y excluyentes. En este marco de ideas, su ideología es excluyente en términos sociales, dicha exclusión la materializan vis-à-vis los migrantes que provienen del mundo no occidental, y cuyo color de piel no es blanca. En 
este grupo social se encuentran los musulmanes y africanos, aunque otras nacionalidades del mundo emergente o menos desarrollado no escapan al rechazo.

Por otro lado, valdría la pena preguntarse por qué los partidos políticos de ultra derecha se han fortalecido tanto en los últimos años, e inclusive han logrado colocarse entre las principales fuerzas políticas en algunos miembros de la UE muy importantes, tales como: Austria, el Reino Unido, Dinamarca, Francia, Hungría, Polonia, así como en la República Checa. Sin duda alguna, estas agrupaciones políticas agrupan entre sus seguidores a personas que rechazan a los refugiados políticos, la migración indocumentada, las crisis económicas, el terrorismo. Sumado a esto, están insatisfechos con el desempleo y las desigualdades sociales que crecen cada vez más en un continente en donde por muchos años las clases medias dominaron el contexto social y económico (Torrecilla, 2015, p. 57). Asimismo, estos partidos políticos han incrementado el número de sus seguidores, debido a la insatisfacción que existe en la opinión pública europea hacia la UE y sus políticas supranacionales. Cabe mencionar que las principales insatisfacciones en relación con la UE son inherentes a la apertura de fronteras, la política migratoria, la libre circulación de personas y la libre circulación laboral. Otra política que rechazan es la relativa a las contribuciones que tienen que derogar sus Estados en relación con los fondos europeos de cooperación interregional. En efecto, dicha insatisfacción constituyó una de las principales causas que propiciaron el fenómeno del Brexit.
En los miembros de la UE de Europa occidental estos son los partidos políticos de ultra derecha que han ganado mayor peso en sus respectivos contextos políticos internos: "Verdaderos Finlandeses" (Finlandia), "Frente Nacional" (Francia), "Partido de la Libertad" (Holanda), "Liga Norte" (Italia), "Amanecer Dorado" (Grecia), "Partido por la Independencia del Reino Unido" (Reino Unido), "Demócratas de Suecia" (Suecia), "Alternativa para Alemania" (Alemania), "Partido Popular Danés" (Dinamarca), "Partido por la libertad de Austria" (Austria), y "Vlaams Belang" (Bélgica). Por otro lado, en los nuevos miembros de la UE de Europa del Este, los siguientes partidos políticos de ultra derecha adquieren cada vez mayor poder y en algunos países como en Polonia, Hungría y la República Checa, constituyen actualmente la principal fuerza política, o una de las más importantes: Entre estos partidos políticos resaltan: "Gran Rumanía" (Rumanía), "Partido Nacional Esloveno" (Eslovenia), "Partido Nacional Eslovaco" (Eslovaquia), "PIs" (Polonia), "Fidesz Unión Cívica Húngara” (Hungría), "Movimiento por una Hungría Mejor" (Hungría), "Libertad y Democracia Moderna” (República Checa), "Unión Nacional Ataque" (Bulgaria), "Partido Popular Conservador" (Estonia), "Unión Nacional" (Lituania), y"Patria y Libertad por Letonia" (Letonia).

Esta cantidad tan considerable de partidos políticos de ultra derecha y su ubicación en el mapa político europeo se puede observar en el Mapa 1, relativo a la ubicación geográfica de dichos partidos. 
112

Mapa 1

La extrema derecha en Europa

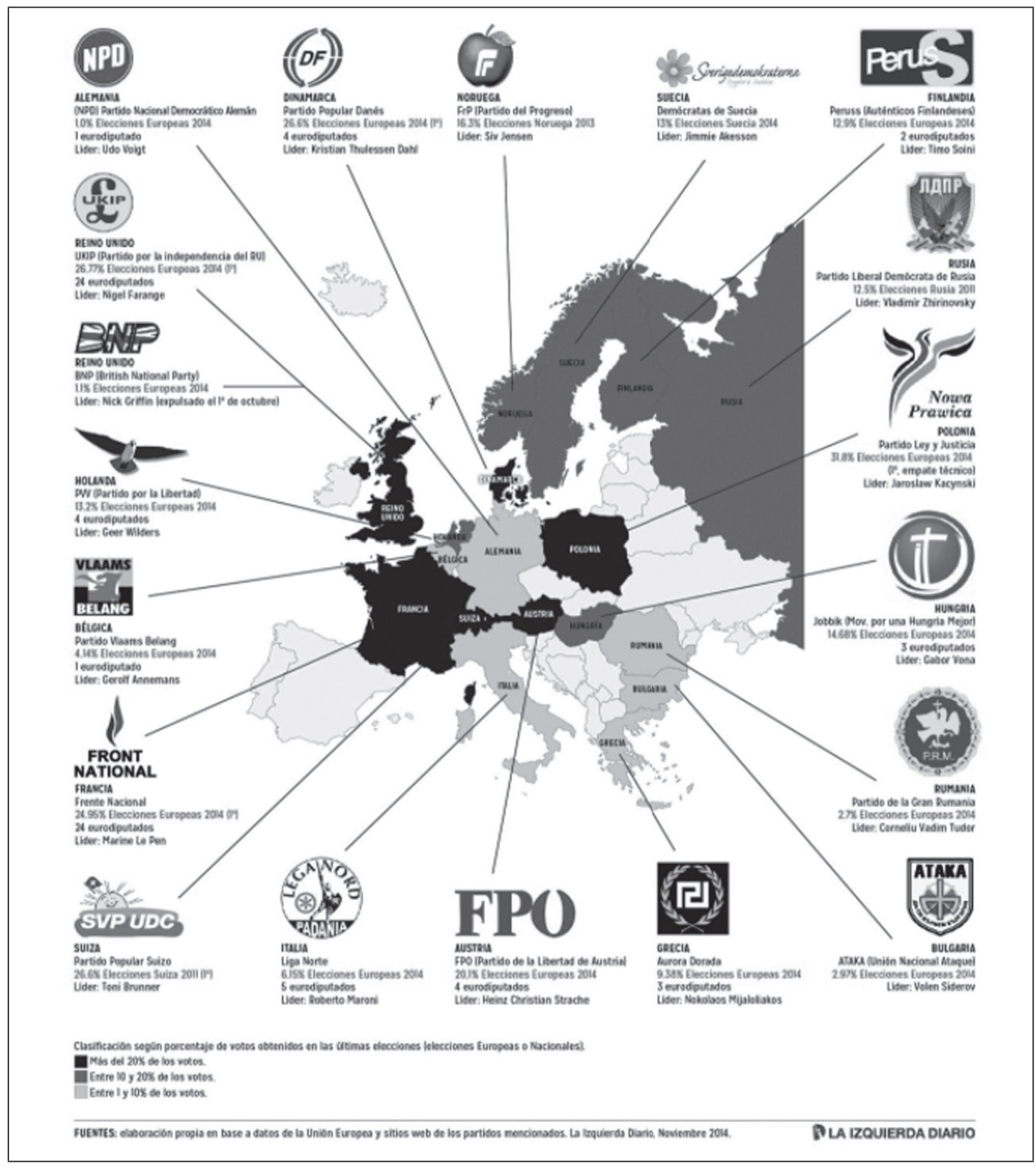

Fuente: Diario la Izquierda, noviembre 2014, https://www.laizquierdadiario.com/IMG/arton5540.jpg 
Cabe mencionar que los partidos políticos más radicales son el "Partido por la libertad de Austria" (Austria), "Frente Nacional" (Francia), "Alternativa para Alemania" (Alemania), "Amanecer Dorado" (Grecia), "Partido por la Independencia del Reino Unido" (Reino Unido), "Ley y Justicia” (Polonia), así como el "Partido por una Hungría Mejor" (Hungría).

Entre sus ideales políticos resaltan:

- Utilizar la fuerza y la capacidad militar europea para detener a los refugiados políticos que intentan ingresar al viejo continente. De no ser así Europa sufrirá las consecuencias de la "islamización".

- Demostrar la superioridad étnica europea frente a otras culturas no occidentales, que ponen en el peligro la "pureza de la civilización europea”.

- Modificar las constituciones internas en aras de limitar la democracia.

- Utilizar la pena de muerte en los casos que sea necesario.

- Rechazar las políticas migratorias de la UE.

- Considerar a los gitanos y a los musulmanes como personas non gratas.

- Se manifiestan en contra de la unión de personas del mismo sexo y del aborto.

- Por lo general, se manifiestan euroescépticos.

- Defienden la idea de construir "muros" o "vallas", en aras de cerrar físicamente las fronteras de Europa vis-à-vis la migración indocumentada, el ingreso de refugiados políticos, e inclusive de personas de culturas no occidentales que ponen en peligro la "civilización y los principios" de la cultura occidental europea.

- En ocasiones utilizan un discurso pro nazi y evocan a Hitler en sus manifestaciones políticas.

- Algunos de estos partidos se declaran abiertamente homofóbicos, racistas y xenofóbicos.

\section{El auge de los partidos políticos de ultra derecha en Europa}

Los siguientes partidos políticos de ultra derecha han incrementado considerablemente su peso en los parlamentos de sus países. Entre estos partidos resaltan: "Partido por la libertad de Austria" (Austria), "Alternativa para Alemania" (Alemania), "Partido por la Libertad" (Holanda), "Libertad y Democracia Moderna" (República Checa), "Frente Nacional” (Francia), "Ley y Justicia” (Polonia), "Movimiento por una Hungría mejor” (Hungría), Partido liberal de Austria" (Austria), "Partido Popular Danés" (Dinamarca), "Partido del Pueblo Suizo" (Suiza) y "Demócratas Suecos" (Suecia). Este considerable aumento de poder e influencia puede ser observado con el aumento del número de sus diputados en sus respectivos parlamentos, así como con los resultados de las últimas elecciones generales en Europa, tal y como se pude apreciar en las gráficas 2 y 3 . 
Gráfica 2

El auge de la extrema derecha en los parlamentos europeos

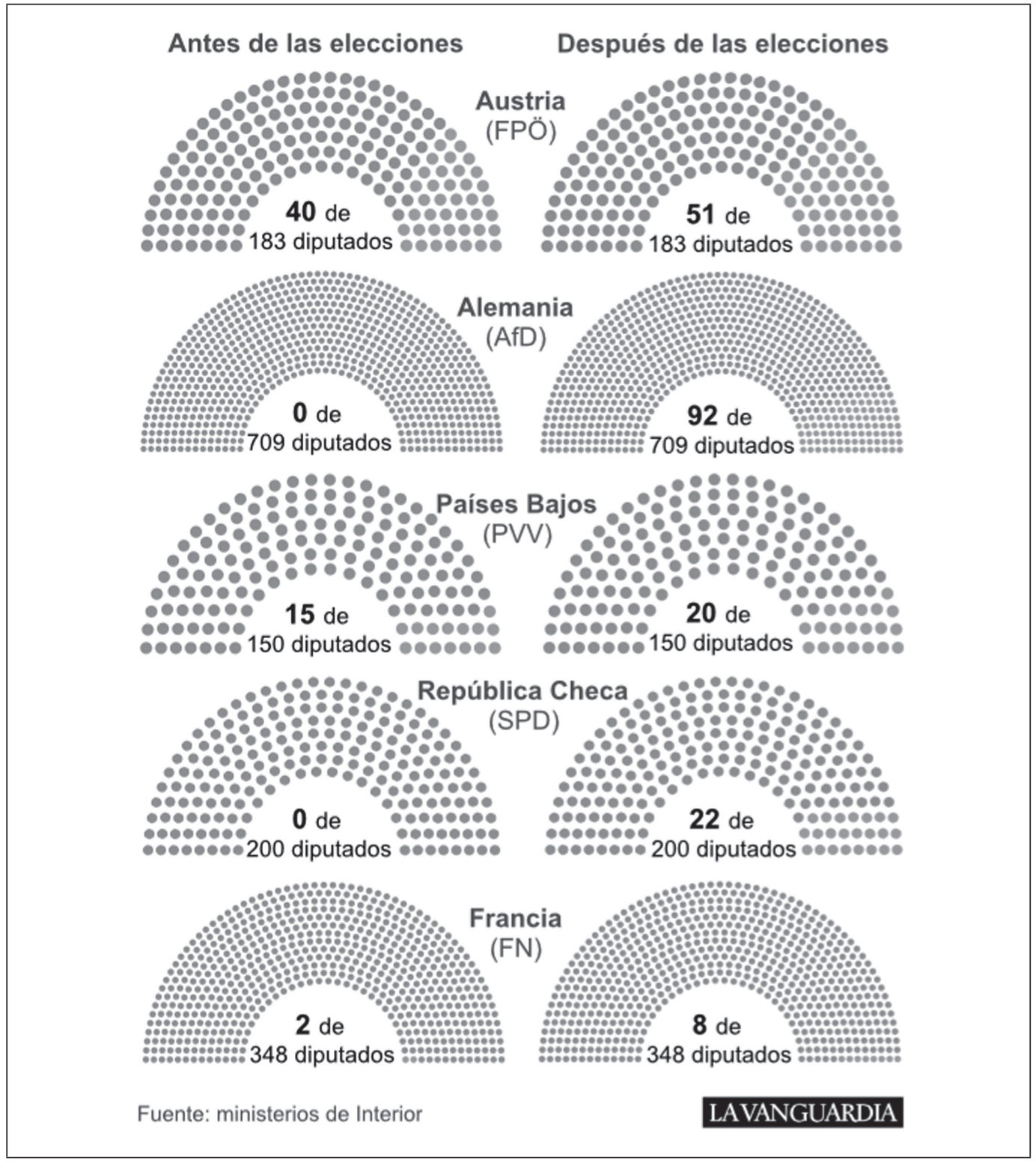

Fuente: La Vanguardia, 2017, https://www.lavanguardia.com/internacional/20171028/432372340603/asi-avanzaextrema-derecha-europa.html 


\section{Gráfica 3}

\section{Resultados obtenidos por los partidos políticos de ultra derecha en las últimas elecciones generales en Europa}

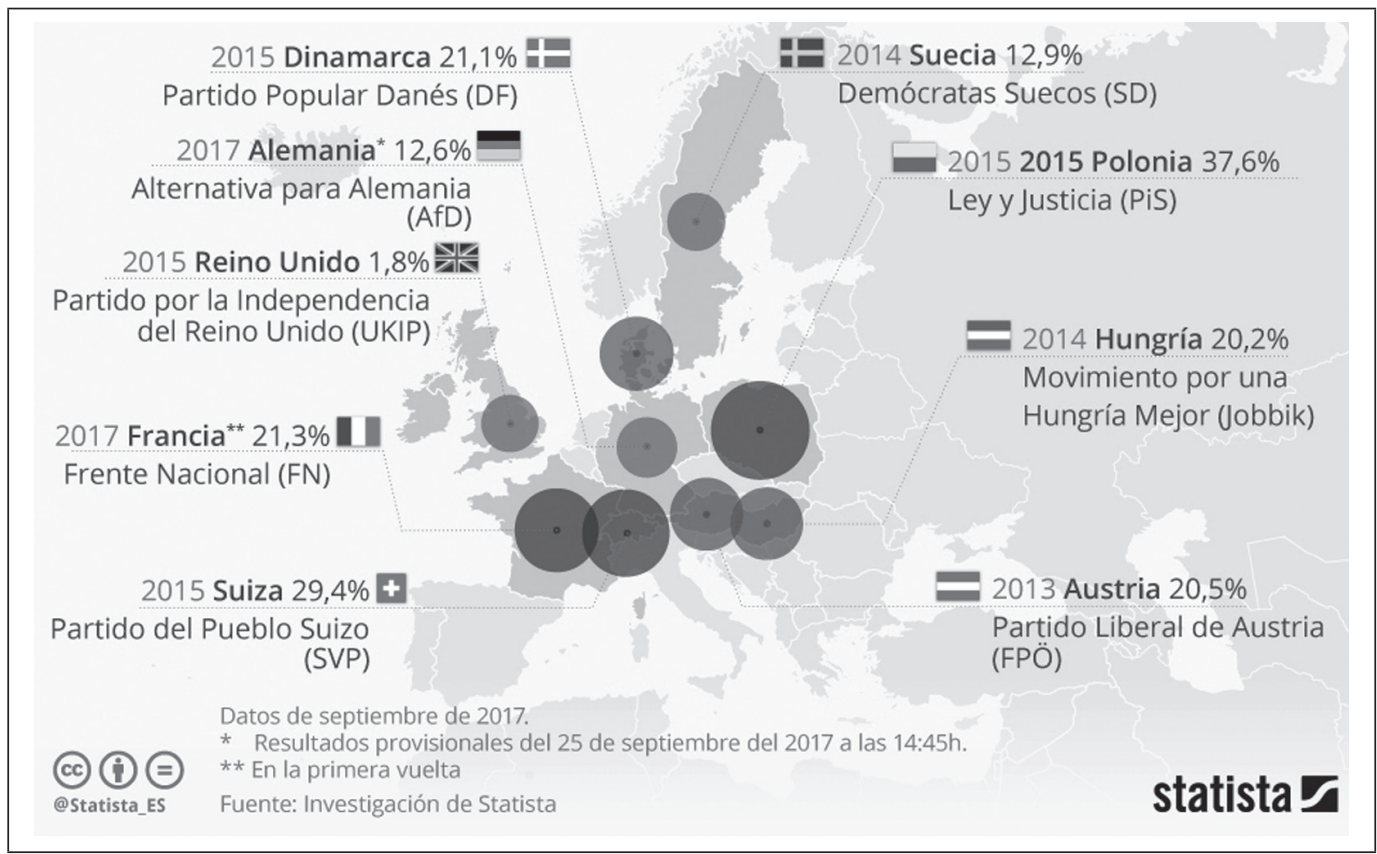

Fuente: El Statista, 2018, https://infographic.statista.com/normal/chartoftheday_11221_el_avance_de_los_partidos_de_extrema_derecha_en_europa_n.jpg

\section{CONCLUSIONES}

La integración de los países de Europa del este en la UE ha propiciado crecimiento, desarrollo económico en las naciones ex satélites de la URss. Además, su incorporación en la UE ha transformado radicalmente el sistema político, económico y social en este grupo de países, en donde imperó hasta 1991 el totalitarismo y la economía de Estado.

Se puede afirmar la hipótesis que se menciona en la introducción de este artículo, que hace alusión a que la membresía de la UE ha tenido resultados muy positivos para los países de la otrora Europa del este, que ingresaron en la UE durante el 2004, 2007 y 2013. Así, las últimas ampliaciones de la UE han contribuido a reducir los niveles de pobreza en las sociedades ex socialistas de Europa y han incrementado la calidad de vida de sus ciudadanos, tal y como lo evidencian los indicadores de la ONU en relación con el índice de calidad humana a nivel mundial. Como se aludió en este artículo los nuevos miembros de la UE 
de Europa del este poseen la mejor calidad de vida en el mundo emergente, debido a que las economías de este grupo de países son consideradas como de "alto desarrollo económico y social". En este sentido, se puede afirmar la siguiente hipótesis. Es decir, que, si estos países no se hubiesen integrado en la UE, muy probablemente hoy en día predominaría in situ la inestabilidad política, el poco crecimiento económico, los conflictos étnicos, así como la fragmentación política de los Estados, tal y como ha sucedido en la mayoría de los países que conforman hoy en día la "nueva Europa del este". En suma, Bielorrusia, Moldavia, Ucrania y Rusia.

Por su parte, la UE también se ha beneficiado de las ampliaciones hacia los países ex satélites de la URss. En este sentido, hoy en día es mucho más grande, más rica en términos económicos y considerablemente más influyente en el escenario político internacional. Desde esta perspectiva, el mercado comunitario se incrementó a 512 millones de personas y las economías de los nuevos miembros de la UE son cada vez más atractivas para sus socios comunitarios, así como para los socios extra comunitarios, debido a las ventajas competitivas que poseen dichas economías, así como por el incremento del poder adquisitivo de los nuevos ciudadanos comunitarios de la UE. Asimismo, el territorio de la UE se amplió en un 35\% y su población aumentó en un $29 \%$.

Por otro lado, el nuevo peso político de la UE se ve reflejado en la posición comunitaria que a veces - no siempre- toman los 28 miembros de la UE en los organismos internacionales, principalmente en el Fondo Monetario Internacional, la Organización
Mundial del Comercio, en la Organización para la Seguridad y la Cooperación en Europa, así como vis-à-vis otras potencias mundiales con quienes rivaliza la UE en materia política, económica, o bien, en cuestiones como en la protección al medio ambiente, como por ejemplo con Estados Unidos. Otro de los grandes beneficios ha sido que Europa occidental es hoy en día mucho más próspera y estable en términos políticos. En este orden de ideas, se logró consolidar la paz, la estabilidad política y económica en los nuevos miembros de la UE, lo que ha tenido asimismo, enormes beneficios para los miembros de la UE de Europa occidental.

Desde la perspectiva de la teoría de la seguridad compleja la incorporación de los países de Europa del este en la UE, se puede comprender teóricamente como un fenómeno de regionalización, cuyo objetivo es el de desarrollar un "sistema de identidad colectiva", en aras de enfrentar, de manera colectiva, los nuevos problemas de seguridad que enfrenta el viejo continente en siglo XXI. En relación con los "nuevos problemas de seguridad" que enfrenta actualmente la UE, se puede mencionar: el terrorismo, el crimen organizado, los partidos políticos de ultra derecha, las autocracias en los países de la "nueva Europa del este", la migración, el desempleo, así como la eventual fragmentación política de los Estados.

Los partidos de ultra derecha no son nada nuevos en Europa. Sin embargo, en los últimos años han incrementado su peso en sus respectivos países. Cabe hacer alusión a que este fenómeno se refleja con el número de diputados que los representan en los parlamentos europeos. 
El aumento del poder e influencia política de los partidos de ultra derecha en Europa ha crecido tanto que hoy en día constituyen la principal fuerza política en países como Hungría, Polonia y en la República Checa. En otros países europeos como en Alemania, Francia, Dinamarca, Grecia, el Reino Unido, Austria y Holanda, los partidos políticos de ultra derecha no dominan el escenario político, empero poseen un gran poder $y$ sus seguidores se incrementan cada vez más.

Cabe mencionar que el perfil de los partidos políticos de ultra derecha en Europa no siempre es igual. Sin embargo, grosso modo comparten características similares y expresan un discurso político que no siempre es el mismo, pero que comparte variables similares. En este orden de ideas, en el argot del discurso político de estos partidos resalta el nacionalismo, la xenofobia, el racismo, la exclusión social y, en algunos casos, como el PIs de Polonia, hasta la homofobia, así como la reafirmación que hace alusión a "Polonia para los polacos". Por otro lado, este tipo de partidos políticos responsabilizan a la UE y a sus instituciones supranacionales de los problemas que enfrentan sus sociedades. Asimismo, están en contra de la migración indocumentada y consideran que los migrantes (documentados o indocumentados) ponen en peligro la esencia de la cultura de sus respectivos países, como es el caso del partido húngaro "Fidesz Unión Cívica Húngara” y del partido checo "Libertad y Democracia Moderna". Cabe mencionar que ambos partidos políticos han puesto en el centro de su discurso político "la lucha en contra de la islamización de Europa”. La exclusión social, así como el racismo y la xenofobia que muestran estos partidos políticos, ha llamado la atención de la Comisión Europea, así como la de algunos miembros de la UE, que son de la idea de sancionar a Polonia y Hungría, así como a la República Checa debido a las políticas anti democráticas de los partidos de ultra derecha, que ponen en cuestionamiento los ideales democráticos de la UE.

Por otro lado, los partidos de ultra derecha más radicales de Europa van más allá de la exclusión social y el discurso político en contra de la migración y de la UE. En tenor, proponen la construcción de muros para frenar la migración indocumentada, así como el uso de la fuerza bélica de Europa para enfrentar el problema de la migración y de la "eventual islamización del continente europeo". En algunos casos como el del partido político de extrema derecha: "Movimiento por una Hungría Mejor", proponen modificar la constitución para limitar los principios democráticos. Otros partidos políticos de ultra derecha como "Alternativa para Alemania”, utilizan símbolos nazis y evocan a la superioridad racial aria vis-à-vis otras culturas o nacionalidades del mundo.

Sin duda alguna, el auge de los partidos políticos de ultra derecha y del nacionalismo de ultranza en Europa pone en peligro la estabilidad política de todo el continente europeo. Asimismo, constituyen una seria amenaza hacia la integración europea, así como a los esfuerzos tan grandes que se han llevado a cabo en Europa, después de la segunda guerra mundial y de la guerra fría, un continente en donde predomine la paz, la estabilidad política, la prosperidad económica, así como respeto a los derechos humanos y a las minorías. 


\section{REFERENCIAS}

Baas, T. y Brücker, H. (2011). EU Eastern Enlargement: The Benefits from Integration and Free Labour Movement. CESifo DICE Report, 9, No. 2.

Baas, T. y Brücker, H. (2010). Labour mobility in the enlarged EU: Who wins, who loses? In EU Labour Markets After Post-Enlargement Migration. Springer: Berlin: Heidelberg, 47-70.

Beacháin, D. Ó.; Sheridan, V. y Stan, S. (2012). Life in Post-communist Eastern Europe After EU Membership: Happy Ever After? vol. 37. Routledge.

Bejaron, R. (25/04/2017). "Los replicantes". Recuperado el 30 de abril de 2018 en: https://www. losreplicantes.com/articulos/partidos-extremaderecha-europa/

Buzan, B. (2007). People, States and Fear: an agenda for international security in the post cold war era, Colchester: ECPR.

Buzan, B. y Waever, O. (2013). Regions and Powers: a guide to global security order, Cambridge: Cambridge University Press.

Buzan, B.; Waever, O. y Wilde, J. (1997). Security: a New Framework for Analysis, Boulder: Lynne Rienner Publishers.

Diario La Izquierda. (11/2014). Recuperado el 10 de junio de 2018 en: https://www.eldiario.es/internacional/ extrema-derecha-Europa_0_683131814.html

Doyle, M. (1986). Liberalisation and World Politics, American Political Science Review, vol. 3.

El Statisa (2018). Recuperado el 12 de junio de 2018, en: https://es.statista.com/grafico/11221/el-avancede-los-partidos-de-extrema-derecha-en-europa/

European Higher Education Area. (2014). European Approach for Quality Assurance of Joint Programmes (October 2014, endorsed by the BFUG, subject to approval by EHEA ministers). October,
2014 [Available at http://www.ehea.info/newsdetails.aspx?ArticleId=365].

Eurobarómetro. (2017). Cinco aspectos de la encuesta paneuropea. Recuperado el 3 de mayo de 2018, en: http://www.europarl.europa.eu/news/es/ headlines/eu-affairs/20170502STO73030/eurobarometro-2017-cinco-aspectos-de-la-encuestapaneuropea

Graham, A. F. (Eds.) (2009). Enlarging the European Union: Effects on the New Member States and the EU, Brussels: Trans European Policy Studies Association.

Hill, C. (2002) "The geopolitical implications of enlargement”. In Jan Zielonka (Ed.), Europe Unbound: Enlarging and Reshaping the Boundaries of the European Union. London: Routledge: 95-116.

Kellerman, A. (2006). The Impact of EU Accession on the Development of Administrative Capacities in the States in Central and Eastern Europe: Similar Developments in Russia? Romanian Journal of European Affairs, vol. 6, No. 3.

La Vanguardia. (2017). La columna de Europa gira a la extrema derecha. Recuperado el 11 de junio de 2017 en: https://www.lavanguardia. com/internacional/20171028/432372340603/ asi-avanza-extrema-derecha-europa.htmlhttps://www.lavanguardia.com/internacional/20171028/432372340603/asi-avanza-extrema-derecha-europa.html

Lewis, P. G. (2006). Party systems in post-communist Central Europe: patterns of stability and consolidation. Democratization, 13, No. 4.

Pacce, M. \& Pacce, V. (2016). El resurgimiento de la extrema derecha en Europa. Recuperado 23 de abril de 2018, de Observatorio de Política Internacional, Sitio web: http://www.ucsf.edu.ar/wp-content/ uploads/2017/01/Pacce.pdf 
Tupy, M. L. (2003). EU enlargement: costs, benefits, and strategies for Central and Eastern European countries. Policy Analysis Review, September 18, No. 489.

Torrecilla, E. (2015). El avance de la ultraderecha en la Unión Europea como consecuencia de la crisis: una perspectiva del contexto político de Grecia y Francia según la teoría del "chivo expiatorio". Madrid: CEU Ediciones.

United Nations Development Programme. (2017) Human Development Index and its Components.
[Available at http://hdr.undp.org/es/content/ table-1-human-development-index-and-its-components].

Weise, B. y Toepel, K. (2001). The Impact of EU Enlargement on Cohesion, Final Report, European Commission Tender No. PO/00-1/RegioA4 DIW. German Institute for Economic Research and European Policies Research Center: Berlin and Glasgow.

Zielonka, J. (2008). The quality of democracy after joining the European Union. East European Politics \& Societies, 21, No. 1. 